\title{
Valoraciones y significaciones acerca del movimiento del dinero en una economía de consumo local
}

\author{
Valuations and meanings concerning the movement \\ of money in a local consumption economy
}

\author{
Gerardo Enrique García Sepúlveda*
}

\begin{abstract}
Resumen: En este artículo se vierten algunas reflexiones sobre las nociones y significados que adquiere la circulación del dinero en un ámbito local específico. Los resultados que se exponen aquí se derivan de una investigación que se encuentra en curso acerca del ahorro y la inversión en la vida cotidiana. Se pretende ofrecer una mirada sobre las distintas lógicas que acompañan a los flujos del dinero, así como las valoraciones y percepciones con respecto a sus dinámicas. En última instancia, esto se relaciona con aquello que los sujetos entienden como situación económica y velocidad en el movimiento del dinero. Se ha llevado a cabo un ejercicio etnográfico y se han ejecutado, la participación-observante, el registro detallado en diarios y entrevistas abiertas. El sitio de trabajo en campo es San Miguel de Cuarenta, una localidad ubicada en el municipio de Lagos de Moreno en el estado de Jalisco, México.
\end{abstract}

Palabras clave: Dinero. Valoraciones. Significaciones. Circulación. Consumo local.

Abstract: This paper contains some reflections concerning notions and meanings on money circulation in a specific locality. The results I present are based on an ongoing research focused on savings and investment in daily life. I explore different logics that run alongside money flows, valuations and perceptions regarding their dynamics. Ultimately, this relates to what the subjects understand as economic situation and speed in the movement of money. I have carried out an ethnographic exercise and have implemented participant observation, keeping detailed records in diaries, as well as open interviews. The fieldwork site is San Miguel de Cuarenta, a village in the municipality of Lagos de Moreno in Jalisco México.

Keywords: Money. Valuations. Meanings. Circulation. Local consumption.

\footnotetext{
* Licenciado en Economía, maestro en Estudios sobre la Región por El Colegio de Jalisco (Zapopan, Jalisco, México) y estudiante de doctorado en Ciencias Sociales en el Centro de Investigaciones y Estudios Superiores en Antropología Social, México<g.gasep@gmail.com>. Investigación financiada por el Consejo Nacional de Ciencia y Tecnología (Conacyt), México.
}

Civitas, Porto Alegre, v. 17, n. 1, p. 79-95, jan.-abr. 2017

Exceto onde especificado diferentemente, a matéria publicada neste periódico 


\section{Introducción}

Un letrero a la orilla del camino anuncia el nombre del pueblo. Sólo hay que recorrer veintitrés kilómetros desde Lagos de Moreno con dirección a Ojuelos. Allí está San Miguel de Cuarenta, con menos de cuatro mil habitantes, resguardado por la presa, los llanos y las montañas que lo circundan. Antes de llegar, desde el puente que cruza el río, se divisan los comercios que custodian cada uno de los lados de la carretera: sitios privilegiados para observar una parte de las dinámicas económicas de la localidad.

Al mediodía entra en el pueblo una camioneta que transporta reses y cerdos para abastecer las carnicerías de la localidad. Los animales deben pasearse vivos antes de llevarlos al recinto donde los sacrificarán. Es una forma de asegurarle a la gente que consumirá carne fresca. No es una simple ocurrencia, ni un rastro de exigencia banal acerca del tipo de alimentos que los habitantes de San Miguel de Cuarenta llevan a sus mesas; es un verdadero ritual en el que se articulan pautas culturales y económicas.

El pueblo se encuentra enclavado en los Altos de Jalisco, una región ligada con las faenas agropecuarias desde que se conformó como tal en el siglo XVI (Fábregas, 1986). La gente aún esgrime ideas, creencias y prácticas asociadas con la ganadería, pues es una actividad que involucra la identidad ranchera (Tomé y Fábregas, 1999). Además, los animales de los establos, en particular los bovinos, representan el sustento principal de algunas familias y el complemento del ingreso de otras. ${ }^{1}$

El ritual del paseo es una expresión tangible de la manera en que se valora la carne. Los elementos socioculturales que intervienen acompañan a las estimaciones monetarias. Asimismo, se delinea una figura particular de comercio basada en la preeminencia de un mercado local. Arturo, quien es propietario de una tienda de abarrotes, fue el primero en señalarme una de las particularidades económicas del ritual del paseo: la carne no se venderá si la gente tiene dudas acerca de su procedencia. Sin embargo, aunque no haya certezas, prevalecerán las compras en los expendios del pueblo por encima de las opciones de abasto que se encuentran en el exterior, con independencia del precio.

En la localidad también se elaboran otros alimentos. El pan y el queso son los ejemplos más representativos. Según Arturo, han llegado

\footnotetext{
${ }^{1}$ En general, la zona se caracteriza por la producción de aves, reses, cerdos, cabras y borregos (cfr. Oficina Estatal de Información para el Desarrollo Rural Sustentable de Jalisco, 2014).
} 
distintos comerciantes de ciudades cercanas ofreciendo el mismo tipo de mercancías, pero tienen pocos clientes. Él no les compra porque ha constatado que se venden mejor los productos que se fabrican en el pueblo. Esta clase de consumo favorece la existencia de un mercado que acota, de manera relativa, los flujos de dinero en un circuito interno. En otras palabras, las dinámicas comerciales en lo tocante a la producción y venta de alimentos en el ámbito local se asemejan a un modelo de economía cerrada (Froyen, 1995). ¿Es posible que esto se explique en virtud de las condiciones económicas que imperan? ¿Acaso se favorece el consumo local como una forma de mantener el dinero en circulación al interior del pueblo?

Las principales ocupaciones son la agricultura, la ganadería y algunos oficios. Muchas personas encuentran empleos en comercios y fábricas de Lagos de Moreno (cabecera municipal). Otras tantas trabajan a destajo en actividades específicas dentro del pueblo o en las cercanías (granjas avícolas o porcinas, producción de ladrillos, confección de calzado y manufactura de guantes industriales). Los salarios fluctúan entre 800 y 1,200 pesos por semana (entre 42 y 63 dólares estadounidenses); no obstante, los ingresos de las familias se complementan con más de un empleo, vendiendo mercancías por catálogo, abriendo negocios propios o integrando a varios miembros de la familia en el mercado laboral. Al margen de ello, los propios pobladores refieren que los incrementos frecuentes en los precios de bienes y servicios merman sus finanzas domésticas. En este escenario es evidente que se intentará aprovechar el dinero disponible de la mejor manera posible, lo cual implica evitar que se pierda entre los flujos monetarios que discurren fuera del ámbito local.

Es un hecho que el comercio de pan, queso y carne en el pueblo permite mantener el dinero en un circuito interno. Algunas personas consideran que es una forma de evitar las fugas de recursos monetarios. Esto facilita la subsistencia en un entorno caracterizado por los bajos niveles de ingresos (salarios y otras percepciones), pues el dinero se conserva siempre entre las mismas manos. Se trata de una estrategia ligada con la noción de escasez, lo cual supone ejecutar acciones racionales y calculadas (Robbins, 1932). No obstante, más allá de lo evidente, es necesario reflexionar qué implica el movimiento del dinero en un mercado de flujos locales. Es posible que los actores le atribuyan significaciones concretas al dinero y que existan distintas percepciones sobre las dinámicas de los recursos monetarios. Así se configura un esquema que conjuga múltiples valoraciones acerca de los flujos del dinero, lo cual se refleja en la constitución de una 
economía de consumo interno que se vincula con figuras financieras locales-globales.

Mi punto de partida es la idea que niega al dinero como una entidad independiente y con capacidad volitiva: un ser que se reproduce al margen de las fuerzas sociales que le confieren su existencia; es decir, un mito que se destaca por su carácter neutro y natural, ajeno a cualquier elemento simbólico (Hernández, 2015). Por el contrario, considero que las prácticas financieras de la vida cotidiana conllevan un entramado complejo de valoraciones que se gestan en distintas escalas y bajo diferentes procesos: una combinación de factores que se interrelacionan dentro un marco especifico de calculabilidad en el cual toman parte las creencias, las cosmovisiones, las relaciones de poder y los juicios morales (Villarreal, 2009).

El uso del dinero como medida de paridad entre las mercancías reclama importancia en tanto los sujetos lo perciben como un medio necesario. Las prácticas y dinámicas sociales son las responsables de crear y re-crear el valor del dinero en el marco de los enfrentamientos intersubjetivos que se verifican en el curso de la vida cotidiana (Long y Villarreal, 2004). Se trata de apreciaciones simbólicas impresas en el dinero en virtud de pautas culturales ligadas con los procesos económicos (Parry y Bloch, 1989); es decir, valores y características diferenciados que se aplican al dinero en cada entramado social (Zelizer, 2011).

Es posible, por lo tanto, que existan diversos circuitos de intercambio y que algunos (o todos) ni siquiera se finquen en la permuta de dinero o bienes materiales (Godelier, 1974). Esto es así porque "[...] los llamados motivos económicos surgen del conjunto de la vida social" (Polanyi, 1975, p. 76). Por ello, las transacciones mediadas por el dinero se forjan en torno a diversas valoraciones sociales, simbólicas y económicas, lo cual redunda en figuras concretas ligadas con el movimiento de los flujos pecuniarios (Long y Villarreal, 2004).

Los resultados que se presentan aquí, se derivan de una investigación en curso acerca del ahorro y la inversión en la vida cotidiana. Dicha pesquisa se fundamenta en los métodos y técnicas propios de la antropología. Prima el ejercicio etnográfico, pero también he recurrido a la participación-observante (Becker y Geer, 1982, citado por Guber, 2001, p. 60) y a las entrevistas abiertas. Los informantes se eligieron con base en un muestreo por cadena de referencia (Mendieta, 2015) y el criterio principal para seleccionarlos fue su ocupación. Se dio prioridad a los comerciantes, aunque también participaron trabajadores asalariados; además se consideraron los datos que ofrecieron un par de unidades domésticas. 


\section{Dinero contante y sonante}

“¡Aquí no es banco!”. Quienes estábamos presentes reímos por el ingenio de la expresión. El dependiente de la tienda se estaba negando a cambiar sus monedas por un billete. Él necesita dinero fraccionado para facilitar las transacciones que realiza a diario, así que le asistía la razón para no realizar la permuta. Esta es una escena cotidiana. La gente prefiere la liquidez que les proporcionan los recursos monetarios en efectivo porque es el medio habitual de pago en San Miguel de Cuarenta. Es consabido que la mayoría de los bienes y servicios sólo pueden adquirirse con billetes y monedas; es decir, con dinero contante y sonante. Ni siquiera los comercios más grandes o con ubicaciones estratégicas (a la orilla de la carretera) aceptan otras formas de pago.

El único cajero automático que hay en el pueblo se atesta de clientes los sábados. Los empleados de fábricas y granjas reciben su salario en una cuenta bancaria. Utilizan las tarjetas de débito que les otorga el banco para disponer de su dinero en efectivo, pues es claro que no pueden pagar con ellas en la localidad. Aún así, quienes tienen la posibilidad de usar sus plásticos en los comercios de Lagos de Moreno, prefieren billetes y monedas para sufragar sus gastos. Lo mismo sucede con los ancianos que reciben sus pensiones y apoyos gubernamentales a través de los bancos: sólo utilizan la tarjeta de débito para cobrar en efectivo.

Si bien las transacciones cotidianas se basan en dinero en efectivo, la preferencia por la liquidez no se reduce sólo a una cuestión práctica. La forma en que se concibe el manejo y resguardo de los recursos monetarios, así como su propio uso, se encuentran atravesados por elementos simbólicos concretos (Sahlins, 1988). El dinero en efectivo se liga con un sentido de posesión tangible. Los billetes y las monedas se palpan, despiden un aroma, emiten sonidos. Prevalece una sensación de seguridad auspiciada por la certeza de que se tiene dinero en los bolsillos. La posesión tangible implica que se tiene un respaldo que permite encarar los retos que presenta la vida económica; por lo tanto, poseer no sólo se relaciona con haberes pecuniarios como tal, sino con las pertenencias materiales en general. Al menos en esta faceta del pueblo, hablamos de una sociedad de productores que se preocupa por la subsistencia en el largo plazo antes que en la fugacidad del presente (Bauman, 2007).

Los bienes y los recursos monetarios se protegen para postergar su deterioro el mayor tiempo posible, así como para resguardarlos de uno mismo o de los demás (Roig, 2009). No obstante, los habitantes del pueblo afirman desconfiar de las instituciones financieras (incluyendo cajas populares y 
cooperativas de ahorro) para guardar su dinero. De allí que las cuentas bancarias y el uso de tarjetas de débito sea por demás limitado. Como ya se mencionó, sólo quienes reciben salarios o pensiones las utilizan y por lo regular es para disponer de dinero en efectivo. ¿Acaso esto indica que no hay educación financiera en San Miguel de Cuarenta? (Angulo, 2014).

La educación financiera, tal como se verifica en el pueblo, implica una perspectiva acerca del beneficio monetario propio. La gente asocia las finanzas con los recursos pecuniarios que lleva en el bolsillo. Así, la confianza en las instituciones financieras se evapora en cuanto las personas notan que las cifras no les favorecen. Se considera importante guardar dinero para cualquier imprevisto, pero se piensa que este permanecerá ocioso en tanto se encuentre detenido; es decir, no ofrecerá réditos, al menos en un plazo determinado. Además, para que los beneficios que prometen los bancos sean rentables (pago de intereses), el monto reservado debe ser alto. Entonces es conveniente conservar el dinero en casa para aprovecharlo mejor.

Los recursos monetarios que se guardan debajo del colchón están por completo a la mano, así que es posible disponer de ellos en cualquier momento. Aunque la intención sea conservalos, las personas saben que al movilizarlos liberan su potencial. Cuando el dinero entra en circulación se transforma en una fuente de financiamiento para el consumo o para la inversión. Esto es muy importante en la cotidianidad del pueblo porque las transacciones se realizan en efectivo. Es claro que la gente optará por imprimirle movimiento al dinero en aras de incrementar su consumo o su caudal pecuniario.

\section{¿EI sol sale para todos?}

Es cierto que los habitantes de San Miguel de Cuarenta prefieren los alimentos que se elaboran en la propia localidad. Aducen que se trata de una cuestión ligada con el gusto; es decir, una especie de costumbre basada en la esfera sensorial. Según ellos, el sabor y la consistencia del pan que se fabrica en el pueblo no se comparan con los productos de otros sitios. Lo mismo sucede con el queso: sólo las mercancías locales satisfacen el paladar de compradores tan exigentes. Esto no quiere decir que las mercancías que se elaboran afuera (pan y queso) sean malas. La gente reconoce que los quesos producidos en Lagos de Moreno son deliciosos, aunque las diferencias en el sabor les recuerdan en dónde se inscribe su fidelidad. Más allá de la mera explicación biológica, las preferencias de consumo se asocian con la identidad y el orgullo por la producción local (Tomé y Fábregas, 1999).

El discurso general entre los comerciantes del pueblo es que el sol sale para todos. Refieren que los productos locales tienen su propio mercado y 
que no es necesario confrontarse con otros vendedores. Bajo su perspectiva, tampoco hay una competencia al interior de la localidad. Sin embargo, algunas dinámicas comerciales se vuelven interesantes bajo esta concepción-discurso en un sistema de competencia que se supone inexistente. Por ejemplo, los acuerdos incumplidos acerca de ciertas transacciones entre los propietarios de los negocios, ofrecen evidencias que contradicen las alocuciones acerca de un juego colaborativo. Elvira, propietaria de una farmacia, dice que ella siempre tuvo su mente abierta respecto a la ayuda mutua entre los comerciantes. Antes de instalar su negocio notificó sus planes a los dueños de las otras boticas de la localidad. Si bien no estaba solicitando un permiso para abrir su negocio, ella quiso ser cortés. Cada una de las farmacias tenía sus propios clientes y su ámbito geográfico de acción. Empero, pronto se percató que las charlas que sostenía con otros boticarios tenían una doble intención: sus competidores buscaban información acerca de sus precios para eliminarla del mercado local. Además, aprovechándose de la buena voluntad de Elvira, otros farmacéuticos le solicitaron varias veces mercancía prestada con la promesa de devolvérsela con prontitud. Nunca le pagaron, ni en especie ni con dinero. Se fracturó la confianza y, por ende, el esquema cooperativo que Elvira tenía en su mente.

Las oportunidades se abren para todos los que tienen un negocio, pero cada sujeto busca acaparar el mercado. En este maremágnum, el ganador es el que logra atraer más clientes, aún a costa de descalificar a sus competidores del mismo ramo. Se aluden todos los defectos de la competencia: falta de equipo, calidad de los productos, horarios de atención y hasta las características personales del propietario del comercio. Y los clientes toman una postura. No sólo eligen lo que compran y el lugar dónde lo hacen, sino que también descalifican los sitios comerciales que no están dentro de sus preferencias. Entonces a pesar de lo que se diserta, hay una competencia un tanto velada pero muy agresiva, que se vuelca al interior del pueblo.

\section{Comercio adentro y afuera}

Por supuesto, no todo se reduce a competir, pues también hay vínculos comerciales armoniosos. Algunos vendedores proveen sus negocios con las mercancías de las tiendas establecidas en la localidad. Laura Arredondo tiene un negocio de repostería y compra cajas de leche condensada en una de las abarroteras más grandes. Allí consigue un precio más bajo que en Lagos de Moreno o León (Guanajuato). ${ }^{2}$ Ella refiere que le conviene adquirir

${ }^{2}$ León es la ciudad más grande del estado de Guanajuato. Se sitúa alrededor de 61 kilómetros de San Miguel de Cuarenta. Las opciones de compra abundan debido a que alberga 1,238,962 habitantes (Instituto Nacional de Geografía y Estadística, 2010). 
estos insumos en el pueblo porque evita transportarse a otros sitios; además, recibe descuentos adicionales por su fidelidad como clienta. Por su parte, Cirilo Villavicencio compra la carne que necesita para su negocio de tacos en los expendios locales. Él dice que son mercancías de buena calidad, lo cual le asegura que sus clientes quedarán satisfechos. Dado que su relación con el carnicero es por demás cordial, le rebajan el precio de los productos que adquiere. Los insumos cárnicos son más baratos en Lagos de Moreno, pero Cirilo prefiere satisfacer a sus clientes a costa de ganar unos pesos más.

Ahora bien, Laura dice que el queso que necesita para preparar sus mercancías lo compra con un proveedor de Lagos de Moreno. No le agradan mucho el sabor y la calidad, pero es una alternativa que favorece su bolsillo por ser más barata. El queso de producción local lo adquiere sólo para los miembros de su familia, así que el dispendio no es tan oneroso. Cirilo, mientras tanto, comenta que su familia consume la carne que se consigue en el pueblo. Sin embargo, las tortillas que requiere para preparar los tacos que vende, las adquiere con un repartidor de Lagos de Moreno. Él considera que las tortillas locales son buenas, pero las que elaboran en la tortillería foránea son mejores para sus propósitos: amén de que son más grandes, su textura mejora el sabor de los alimentos que prepara.

Es claro que las alternativas de consumo no se reducen sólo a las mercancías que ofrecen los productores locales. La panadería ubicada en la ciudad de Ocampo ${ }^{3}$ también tiene clientes en el pueblo; por ejemplo, Doña Teresita Vargas, quien adquiere sus productos porque siente nostalgia. Ella es oriunda de aquella localidad, así que revive su infancia cada vez que paladea su pan. Según Doña Teresita, los bollos con piloncillo ${ }^{4}$ son una prueba de la verdadera maestría con que trabajan los tahoneros de su tierra. Pero también hay compradores originarios de San Miguel de Cuarenta que prefieren el pan de Ocampo, aunque su decisión se basa en cálculos de conveniencia monetaria: las hogazas son más grandes y pagan lo mismo por ellas.

La jactancia por las mercancías que se elaboran en el terruño pasa a segundo término cuando los bolsillos imponen sus límites. Laura comenta que los padres de familia escogerán el pan más barato porque les rinde mejor su dinero. En el mismo sentido, Elvira refiere que la carne congelada que venden en los supermercados de Lagos de Moreno es una buena opción debido a que su precio es asequible. En su caso ella no reconoce diferencias respecto

\footnotetext{
${ }^{3}$ Ocampo es la cabecera de un municipio del estado de Guanajuato que lleva el mismo nombre. Esta localidad se ubica alrededor de 72 kilómetros de San Miguel de Cuarenta.

${ }^{4}$ La informante se refiere a una especie de empanada que se rellena con el dulce referido.
} 
a la calidad de los alimentos que se producen en el pueblo o fuera de él. Su elección se basa en la posibilidad de comprar una cantidad mayor de carne por el mismo precio.

Las influencias del exterior modifican las pautas que se suponen inamovibles en el interior de la localidad. Los discursos imbuidos de orgullo que asignan valor a los productos de elaboración local, se difuminan al enlazarse con otro tipo de estimaciones. La balanza de las decisiones se inclina en la medida que los sujetos evalúan las características de los objetos que comprarán. Adquieren relevancia la marca, la calidad, la conveniencia monetaria o el sitio donde se producen las mercancías; pero, en cualquier caso, los gustos, las costumbres y la identidad no pierden su prevalencia como elementos a través de los cuales se ciernen las preferencias de consumo de la gente.

En este sentido, los circuitos comerciales de San Miguel de Cuarenta también se ligan con escalas que rebasan las fronteras nacionales. Esto implica que el flujo de dinero a través del consumo se inscriba, de manera directa o indirecta, en circuitos extra-locales (incluidos los globales). Un ejemplo de ello es la ropa usada proveniente de Estados Unidos que se vende en la plaza del pueblo los domingos. Este tipo de indumentaria se valora en virtud de la relación precio-marca. Se trata de prendas que portan etiquetas de diseñadores reconocidos, las cuales se ofrecen a precios asequibles. Quienes visten esta clase de ropa apuestan por el estatus social que les reporta la marca, amén de que tratan de aparentar cierta solvencia monetaria. Del mismo modo, tal como me explica Gema Ruelas en una entrevista (4 de junio de 2016), son prendas atractivas para la gente porque concuerdan con los dictados de la moda.

\section{Movimiento del dinero}

¿Cómo llega el dinero a los bolsillos de las personas? La respuesta depende, en gran medida, de la percepción que tienen los sujetos acerca del movimiento del dinero. Gastar dinero implica que se tienen ingresos, reservas o la posibilidad de obtener préstamos. Asimismo, los dispendios suponen la existencia de una contraparte cuyos ingresos se deben a estas mismas erogaciones. ¿Entonces nuestra vida económica se reduce a perseguir el dinero como un medio indispensable para realizar transacciones? ¿Es posible que el dinero sea un titiritero que sujeta los hilos de actuación de las personas? Según Laura, pensar que el dinero mueve a la gente es algo "cruel". Gema opina lo mismo, aunque ella compara la búsqueda desenfrenada del dinero con una percepción equivocada del valor. Es una forma de alienación que subsume a los sujetos en la obsesión de tener cada vez más objetos materiales. Se 
desestiman las consecuencias de rebasar los límites que imponen los valores sociales, morales y religiosos.

En realidad, poseer dinero conlleva una decisión potencial para deshacerse de él, para gastarlo, así que su dinámica se debe a la propia gente. A fin de cuentas, "la gente dice... es la que decide... y es la que hace y sabe... cómo" (Juan Puentecillas, entrevista realizada por el autor el 6 de junio de 2016). El problema es allegarse de los recursos monetarios que se requieren para alimentar los flujos a través de los dispendios. En San Miguel de Cuarenta el origen de la circulación del dinero se concibe a partir de las ganancias monetarias que provienen de: a) la venta de la fuerza de trabajo y b) el comercio. Las retribuciones salariales forman una parte muy importante de los ingresos familiares. Quienes son empleados consideran que es necesario "tener trabajo" para que el dinero se mueva, pero lo mismo piensan quienes se dedican a las actividades comerciales. Los propietarios de negocios valoran los empleos, aunque ellos mismos no detenten uno, porque saben que incrementarán las posibilidades de consumo de la gente. Respecto al comercio, Cirilo refiere que en el pueblo hacen falta negocios, "puestos", para que la gente disponga de mercancías y el dinero se quede en la misma localidad.

El consumo, como una forma de satisfacer deseos y necesidades, es uno de los motores que impulsan los dispendios de recursos pecuniarios. Sin embargo, elegir la forma en que se llevarán a cabo dichos gastos, demanda un cúmulo de cálculos y valoraciones complejos. Esto es así porque los elementos materiales e inmateriales proclives a consumirse, se encuentran acompañados de cargas simbólicas que se gestan en el marco de las relaciones sociales (Featherstone, 1991). Entonces el vínculo ingresos-gastos, como condición indispensable para la circulación del dinero, sólo adquiere sentido a través de las significaciones que los sujetos le imponen. El dinero se mueve pues, gracias a las personas.

El dinero se gana y se gasta para vivir. Esto le concede importancia como un medio que permite a los sujetos participar en un sistema económico mercantilizado (Bazán y Saraví, 2012). En la medida que se carece de recursos monetarios, las personas tienden a evitar gastos; por lo tanto, se limitan los flujos. Según la percepción de la gente, mientras haya menos dinero en circulación, más complicado será atender el consumo. Tal como refiere Ignacio Revilla, cuando las ventas de los negocios disminuyen, es un indicio claro de que no se está moviendo dinero en las calles.

Cuando el dinero falta en los bolsillos de la gente, se piensa que su valor se incrementa. Se convierte en un recurso escaso, codiciable. Más allá de su función como medio para los intercambios, se vuelve un objeto digno 
de poseerse. Su propio valor lo eleva a una categoría de fin deseable. Su importancia se incrementa y se transforma en ser. Adquiere personalidad, al menos en la medida que la gente reconoce sus virtudes. No obstante, el dinero que no se lanza a la circulación acusa cargas morales negativas en San Miguel de Cuarenta. Ni siquiera la escasez justifica que los sujetos atesoren recursos monetarios. El dinero escaso se valora en función de su carácter exiguo, pero no como algo que deba apartarse o retenerse, pues encuentra su máximo potencial en el instante que adquiere movimiento. Por lo tanto, favorecer o limitar su circulación conlleva un esquema de antagonismo moral que abraza a quienes tienen la facultad de propulsarlo o retenerlo (Wilkis, 2013).

Laura comenta que es necesario hacer rendir el dinero. Se debe invertir en actividades que reditúen con ganancias monetarias o no-monetarias. Según ella, es posible que no se obtenga una gran cantidad de dinero; no obstante, aún los excedentes más pequeños son un peldaño para incrementar los caudales. Lo que nunca debe olvidarse, dice Laura, es que una parte de las ganancias debe otorgarse a la Iglesia. Es una muestra de gratitud hacia Dios que será recompensada. Ignacio también opina que el dinero debe circular para que se multiplique. Él piensa que los recursos monetarios fructifican en la medida que cada quien se desprende de ellos. En ambos casos, el desapego a un objeto -dinero- cuyo valor podría ser alto debido a su escasez, se liga con sus creencias religiosas sobre la generosidad. A decir de ellos, el dinero que se deja ir vuelve con creces.

Elvira también es creyente. Ha comprobado que desprenderse del dinero trae consigo réditos pecuniarios y espirituales. No obstante, por contradictorio que parezca, ella piensa que el dinero que se va ya no regresa. Se supone que los recursos monetarios dan vueltas y tarde o temprano retornan. Esa es la idea de lanzar el dinero a la circulación, lo cual Elvira reconoce como cierto. El problema es, según ella, hacia dónde se dirige el dinero; es decir, en cuál vía de flujo se inyecta. Cuando lo recursos monetarios se gastan, hay que olvidarse de que volverán por ningún medio. Sólo la inversión, como dinero en movimiento, asegura que se recuperará el capital y que se obtendrá un beneficio adicional. Esto es debatible en virtud de que el gasto provee a las personas de bienes y servicios, amén de satisfacciones. Empero, resalta la importancia de mantener constante el flujo de dinero, ya sea a través del gasto o de la inversión.

\section{Lentitud y rapidez}

Decido sentarme frente a Raymundo "Búfalo" Centeno en el dintel de la entrada de la tienda. El pueblo transpira demasiada quietud. Se lo comento 
y él concuerda conmigo. Dice que esta serenidad es la prueba indefectible de que la gente no ha recibido su salario quincenal. Cada dos semanas, entre los días miércoles y viernes, esta situación también coincide con la falta de pago del salario sabatino. La actividad en las calles disminuye. Según Arturo, son semanas complicadas para el comercio, pues hay poco dinero en circulación. Las personas prefieren evitar los gastos unos días antes de recibir su paga. Es una forma de estirar los recursos monetarios que aún les quedan.

Estos ciclos de calma se reiteran también en fechas especiales. Elvira, quien ha sido comerciante por más de 25 años, ha notado que circula menos dinero después de las festividades. Su negocio de cosméticos y perfumería le reporta pingües beneficios una semana antes de las fiestas patronales, de la Navidad y del día de la madre. En esas fechas la gente se vuelca en las compras. Después de cada una de estas celebraciones sigue un período de dos semanas en las que no hay ventas. Elvira piensa que las personas experimentan inquietud por haber gastado su dinero: "Nada más les dura [dos semanas]... me imagino yo como que la sensación de culpa [por comprar]...". ${ }^{5}$ Ella considera que la disminución de las ventas no se debe a la falta de dinero, sino a la mala administración de los recursos pecuniarios. Lo cierto es que Elvira reconoce que los flujos crematísticos son distintos antes y después de las fiestas, amén de que conllevan una carga moral autoimpuesta.

La percepción que tiene la gente acerca del flujo del dinero es un medidor intuitivo acerca de las condiciones financieras del entorno. Por lo regular, se concibe que el movimiento lento de los recursos monetarios se origina porque los bolsillos de las personas están vacíos. Esto puede deberse a una situación generalizada derivada de contingencias estructurales (por ejemplo, crisis o recesiones); o bien, a ciclos normales asociados con la recepción de pagos y salarios. Empero, las observaciones de los habitantes del pueblo acerca de la circulación de los recursos pecuniarios, también son factores que los impulsan a actuar. La disminución de ventas y la tranquilidad en las calles auguran escasez de dinero. Estas lecturas del sistema de flujos monetarios no son alentadoras porque denotan lentitud en el retorno del dinero que se invierte; es decir, una demora de las ganancias que se espera obtener cuando se destinan recursos pecuniarios a ciertas actividades comerciales o productivas. En el caso del comercio, las mercancías que no se venden y la percepción del dinero que fluye con parsimonia, obligan a limitar los inventarios; por supuesto, esto ralentiza aún más la circulación de los recursos monetarios.

\footnotetext{
${ }^{5}$ Entrevista realizada por el autor (7 jun. 2016).
} 
La lentitud conlleva la rapidez como punto de contraste necesario. Cada domingo el movimiento de la gente se adueña de las calles. El dinero pasa de mano en mano en un ambiente festivo. Quienes salen de paseo fuera del pueblo y quienes se quedan a convivir con amigos rebosan las tiendas durante todo el día. Los bolsos y billeteras, por verse a sí mismos llenos, comparten la alegría de la gente. Los intercambios con altas denominaciones de papel moneda son comunes durante esos días y nadie se turba por lanzarlos a la circulación. La vida se acelera y a la par también lo hace el movimiento del dinero.

La algarabía también se extiende más allá de sus horas habituales cuando circula una mayor cantidad de dinero en la calle. Esto ocurre dos veces por año, durante los días que pasan los peregrinos que se dirigen a San Juan de los Lagos. En particular, la procesión que proviene del norte del país durante la Semana Santa, trastoca la cotidianidad de San Miguel de Cuarenta. Los comercios abren sus puertas más temprano y las cierran hasta muy tarde en la noche (entre doce y una de la madrugada); inclusive, quienes viven a la orilla de la carretera, velan cada miércoles Santo. Vale la pena la vigilia. Los peregrinos traen consigo dinero y llegan a la localidad buscando comida y bebidas calientes. En la casa de Cintia Campos improvisan una fogata alrededor de la cual se reúnen los caminantes. Las ventas de café y tamales ${ }^{6}$ mantienen ocupadas a las moradoras del inmueble, quienes atienden a su clientela con presteza. Con la misma celeridad llega dinero a sus manos. Cirilo, Laura, Arturo y Renato también aprovechan la ocasión. Todos se deshacen de las mercancías que adquirieron con anticipación para fecha tan señalada. Las inversiones regresan casi de inmediato y con creces. Los rostros agotados entrelucen una sonrisa porque los bolsillos están llenos.

\section{Temporadas buenas y temporadas malas}

Los ritmos del pueblo transcurren así, entre temporadas buenas y malas. La percepción general es que mientras más dinero haya en circulación, la suerte financiera les favorecerá a todos. Los periodos malos se caracterizan por un letargo en las dinámicas económico-financieras. El dinero, bajo la forma de mercancías, se queda detenido en los estantes, en los aparadores y en las neveras. Los recursos pecuniarios que se invierten, dilatan en regresar. Por el contrario, los periodos buenos se distinguen por la rapidez con que se recibe dinero, ya sea por la venta de mercancías o de servicios. Y en estos casos se abre una disyuntiva acerca de las ganancias monetarias: ¿se deben guardar

\footnotetext{
${ }^{6}$ Alimento típico. En San Miguel de Cuarenta los tamales son tortas elaboradas con masa de maíz rellenas de carne, queso o vegetales, envueltas en hojas de maíz y cocidas al vapor.
} 
o se deben re-invertir? En otras palabras, ¿se deben preservar, retirándolas de la circulación? O bien, ¿se deben movilizar, inyectándolas en las venas por las cuales transitan los flujos? Es posible que existan fundamentos racionales para que el dinero entre en circulación: promueve la actividad económico-financiera; en particular, las transacciones compra-venta de toda clase de mercancías (incluida la fuerza de trabajo). No obstante, las sanciones morales que prevalecen en San Miguel de Cuarenta obligan al movimiento del dinero en función de cargas sociales y simbólicas. Es una muestra de acierto y ecuanimidad respecto al uso de los recursos monetarios en la cual prevalece el sentido de la vida por encima del interés material. Tal como afirma Ignacio, "si dejas que el dinero te mueva [...], te metalizas [...] Para esa persona [metalizada] el dinero es todo [...] se olvida de lo demás, hasta de divertirse como debe ser... por miedo de que su capital se le vaya a... terminar". ${ }^{7}$

La dinámica del dinero y la percepción de la velocidad de los flujos se asocian con la situación económica que prevalece en el entorno. "Melvin", empleado de una ladrillera, piensa en los trabajos de construcción que está realizando en su casa cuando hablamos de la situación económica. Dice que su apreciación es muy buena porque no ha encontrado albañiles para contratarlos. Los brazos están ocupados y están recibiendo ingresos, lo cual indica que el dinero está circulando. Sin embargo, esto sólo es una perspectiva que domina el ámbito local. Además de "Melvin", la mayor parte de mis informantes reducen la situación económica a sus propias circunstancias -personales y domésticas-. ¿Por qué hay personas que no distinguen lo que ocurre en otras escalas? Es posible que sólo atiendan los elementos tangibles que les permiten formarse una opinión sobre ello; en particular, las cantidades de dinero contante y sonante que pasan por sus manos. Por supuesto, hay quienes advierten los nexos entre la situación económico-financiera que se verifica en otros sitios y la propia; no obstante, terminan por basar sus percepciones en la cantidad de dinero que cargan en sus bolsillos.

¿Y las interrelaciones financieras con el extranjero? A pesar de los altos índices de migración hacia Estados Unidos en la zona, es necesario aclarar que muchas familias no reciben remesas. Se disertan la conveniencia del tipo de cambio de las divisas y las ventajas que se ofrecen a quienes poseen dólares. Empero, en el escenario cotidiano predomina el uso de la moneda nacional. Las cargas simbólicas que se le asignan al dólar se corresponden de manera exacta con las sanciones morales que se le imprimen a los flujos pecuniarios.

\footnotetext{
${ }^{7}$ Entrevista realizada por el autor (8 jun. 2016).
} 
Quienes han regresado del norte desbordando billetes verdes, están sujetos a la obligación -moral- de lanzarlos a la circulación (convertidos en pesos, por supuesto). Y es consabido que se debe actuar de esa manera. Así lo entienden "Quetzal” Molina y "Búfalo” Centeno, quienes cambian sus dólares por pesos mexicanos para insertarse en la vida comercial de San Miguel de Cuarenta. El primero agota las reservas que reunió mientras trabajaba en el extranjero y el segundo gasta su pensión estadounidense. Los vínculos financieros locales-globales se filtran, por lo tanto, a través del movimiento que supone la conversión monetaria.

\section{Notas finales}

Las personas deciden cómo y en qué dirección movilizarán los recursos monetarios que poseen. La dinámica de los recursos pecuniarios, por lo tanto, se relaciona con valores, significados y percepciones que se enmarcan en un contexto sociocultural específico. En el caso de San Miguel de Cuarenta se concibe que el dinero debe inscribirse en los circuitos de flujo para aprovecharlo. Si el dinero se retiene, también se obstaculiza el intercambio de mercancías (incluida la fuerza de trabajo), lo cual repercute en las condiciones económico-financieras de las familias que habitan en la localidad.

El destino de los flujos tiene consecuencias que traspasan la esfera utilitaria del dinero. La propia concepción de los recursos pecuniarios y el modo en que se les imprime movimiento, comportan distintas facetas ligadas con el ejercicio del poder. Asimismo, entran en juego sanciones morales que definen el carácter obligatorio y la pertinencia de la circulación del dinero. Más allá de los beneficios monetarios, se apela a un sentido particular sobre la continuidad de la vida material.

La evidencia empírica sugiere la existencia de una economía de consumo local en la cual priman la identidad y el orgullo por lo que se considera propio. No obstante, las dinámicas pecuniarias que se promueven en el pueblo, terminan por configurar un esquema de conexiones extra-locales que se valora en función de cálculos complejos. El movimiento del dinero se escapa del control de las manos que lo impulsaron en primera instancia. El fantasma de un factor estructural que escinde al dinero de su motor social adquiere un cuerpo material. Las ideas y las buenas intenciones de contener los flujos en un espacio local, se difuminan en el caos que generan las múltiples redes de circulación. El dinero se va y a veces no vuelve.

Sólo queda la percepción del movimiento asociada con la rapidez o lentitud del retorno de los recursos monetarios. Esto basta para hacer girar el dinero en el interior de San Miguel de Cuarenta: se piensa en la circulación 
crematística como una ruleta que favorece a todos, uno por cada vuelta. No podría ser de otro modo porque de ello depende que las cosas marchen bien.

\section{Referencias}

ANGULO, Lourdes. Prácticas financieras riesgosas para afrontar la crisis económica en los hogares: entre malabarismos con el dinero y sobreendeudamiento. Desacatos, v. 44, p. 51-66, 2014.

BAUMAN, Zygmunt. Vida de consumo. México: Fondo de Cultura Económica, 2007. BAZÁN, Lucía y SARAVÍ, Gonzalo. La monetarización de la pobreza: estrategias financieras de los hogares mexicano. México: Centro de Investigaciones y Estudios Superiores en Antropología Social, 2012.

FÁBREGAS, Andrés. La formación histórica de una región: los altos de Jalisco. México: Centro de Investigaciones y Estudios Superiores en Antropología Social, 1986.

FEATHERSTONE, Mike. Cultura de consumo y posmodernismo. Buenos Aires: Amorrortu Editores, 1991.

FROYEN, Richard. Macroeconomía: teorías y políticas. Colombia: McGraw Hill, 1995.

GODELIER, Maurice. Antropología y economía. Barcelona: Anagrama, 1974.

GUBER, Rossana. La etnografía: método, campo y reflexividad. Bogotá: Grupo Editorial Norma, 2001.

HERNÁNDEZ, Carlos. El dios de la modernidad: para una antropología del dinero. Paakat: Revista de tecnología y sociedad, v. 5, n. 8, s. p., 2015.

INSTITUTO Nacional de Geografía y Estadística. Censo de población y vivienda: principales resultados por localidad (Iter), $2010<$ http://www.inegi.org.mx/sistemas/ consulta_resultados/iter2010.aspx?c=27329\&s=est $>$ (29 oct. 2015).

LONG, Norman; VILLARREAL, Magdalena. Redes de deudas y compromisos: la trascendencia del dinero y las divisas sociales en las cadenas mercantiles. In: Magdalena Villarreal (coord..). Antropología de la deuda: crédito, ahorro, fiado y prestado en las finanzas cotidianas. México: Centro de Investigaciones y Estudios Superiores en Antropología Social-Miguel Ángel Porrúa, 2004. p. 27-55.

MENDIETA, Giovane. Informantes y muestreo en investigación cualitativa. Investigaciones Andina, v. 17, n. 30, p. 1148-1150, 2015.

OFICINA Estatal de Información para el Desarrollo Rural Sustentable de Jalisco. Información inventarios ganaderos. Distrito de desarrollo rural 2, correspondiente al área de Lagos de Moreno, 2014 <http://www.oeidrus-jalisco.gob.mx/ganaderia/ inventario/index.php?idcurrent $=2>$ (15 jun. 2016).

PARRY, Jonathan; BLOCH, Maurice. Money and the morality of exchange. Cambridge: Cambridge University Press, 1989.

POLANYI, Karl. La gran transformación. México: Juan Pablos Editor, 1975. 
ROBBINS, Lionel. An essay on the nature and significance of economic science. London: Macmillan, 1932.

ROIG, Alexandre. Separar de sí, separar para sí: aproximaciones a las prácticas de ahorro domésticas en sectores populares urbanos argentinos. Buenos Aires: IdaesUniversidad Nacional de San Martín. Presentado en el Congreso 2009 de la Asociación de Estudios Latinoamericanos, Río de Janeiro, Brasil, del 11 al 14 de junio de 2009 $<$ http://www.pdfio.net/k-54761038.html> (5 nov. 2012).

SAHLINS, Marshall. Cultura y razón práctica. Barcelona: Gedisa, 1988.

TOMÉ, Pedro; FÁBREGAS, Andrés. Entre mundos: procesos interculturales entre México y España. Zapopan, Jalisco: El Colegio de Jalisco, 1999.

VILLARREAL, Magdalena. Mujeres, finanzas sociales y violencia económica en zonas marginadas de Guadalajara. Guadalajara: Instituto Jalisciense de las MujeresInstituto municipal de las Mujeres en Guadalajara, 2009.

WILKIS, Ariel. Las sospechas del dinero. Buenos Aires: Paidós, 2013.

ZELIZER, Viviana. El significado social del dinero. Buenos Aires: Fondo de Cultura Económica, 2011.

Recibido el: 18 jul. 2016

Aprobado el: 15 dic. 2016

Autor correspondiente:

Gerardo Enrique García Sepúlveda

C.P. 45200, Zapopan, Jalisco, México 